\title{
PEMETAAN GEOGRAPHIC INFORMATION SYSTEM (GIS) KERUSAKAN POHON PADA BERBAGAI FUNGSI HUTAN DI PROVINSI LAMPUNG
}

\author{
MAPPING GEOGRAPHIC INFORMATION SYSTEM (GIS) TREE DAMAGE IN VARIOUS \\ FOREST FUNCTIONS IN LAMPUNG PROVINCE
}

\author{
Oleh \\ Prayogi Saiful Anwar' ${ }^{1)}$, Rahmat Safe' ${ }^{2)}$, Arief Darmawan ${ }^{3)}$, Hari Kaskoyo ${ }^{4)}$ \\ ${ }^{1)}$ Mahasiswa Jurusan Kehutanan Fakultas Pertanian Universitas Lampung \\ ${ }^{2,3,4)}$ Staf Dosen Jurusan Kehutanan Fakultas Pertanian Universitas Lampung \\ Jl. Prof. Dr. Ir. Sumantri Brojonegoro, Gedung Meneng, Bandar Lampung 35145 \\ Email : rahmat.safei@fp.unila.ac.id

\begin{tabular}{|l|l|}
\hline Diterima :18 Februari 2021 & Disetujui: 30 Maret 2021
\end{tabular}

\begin{abstract}
Abstrak
Pengelolaan hutan yang lestari bisa dicapai melalui penilaian kesehatan hutan. Penilaian kerusakan pohon bertujuan untuk mengukur tingkat gangguan pada pohon sehingga pada akhirnya kondisi hutan dapat terdeteksi dan pengambilan keputusan oleh para pengelola hutan dapat dilakukan dengan tepat. Penelitian ini bertujuan untuk menilai kerusakan pohon di beberapa fungsi hutan. Penggunaan Geographic Information System (GIS) menjadi vital, dimana sebaran kondisi kerusakan pohon dapat diketahui secara spasial, sehingga dapat dideskripsikan dengan baik. Hasil analisis penelitian menunjukkan hutan konservasi untuk pohon sehat sebanyak 17, pohon sedang sebanyak 30 dan pohon rusak sebanyak 105. Hutan produksi untuk pohon sehat sebanyak 51, pohon sedang sebanyak 82 dan pohon rusak sebanyak 128. Sedangkan untuk hutan lindung kondisi pohon sehat sebanyak 27, pohon sedang sebnyak 75 dan pohon rusak sebanyak 56. Kondisi kesehatan pohon pada beberapa fungsi hutan dalam kondisi rusak dan perlu perhatian dari pengelola hutan. Perlu adanya tindakan oleh pengelola berupa pemeliharaan seperti pemangkasan, pendangiran dan pemupukan serta tindakan pemanenan dengan pemilihan waktu yang tepat.
\end{abstract}

Kata kunci : Pengelolaan hutan, Geographic Information System (GIS), kerusakan pohon.

Abstract

Sustainable forest management can be achieved through an assessment of forest health. The tree damage assessment aims to measure the level of disturbance in the trees so that in the end forest conditions can be detected and decision making by forest managers can be carried out appropriately. This study aims to assess tree damage in several forest functions. The use of the Geographic Information System (GIS) is vital, where the distribution of tree damage conditions can be spatially determined, so that it can be described properly. The results of the analysis showed 17 conservation forests for healthy trees, 30 medium trees and 105 damaged trees. 51 production forests for healthy trees, 82 medium trees and 128 damaged trees. There are 75 medium trees and 56 damaged trees. The health condition of trees in several forest functions is in a damaged condition and needs attention from forest managers. There needs to be action by the manager in the form of maintenance such as pruning, silencing and fertilizing as well as harvesting actions with the right timing.

Keywords: Forest management, Geographic Information System (GIS), tree damage.

DOI:1030598/jhppk.2021.5.1.56

ISSN ONLINE: 2621-8798 


\section{PENDAHULUAN}

Pengelolaan Hutan Lestari untuk masa kini dan masa yang akan datang memerlukan informasi terkait kondisi kesehatan hutan untuk kebutuhan pengembangan pengelolaan hutan (Safe'i et al. 2021). Pengelolaan hutan yang lestari bisa dicapai melalui penilaian kesehatan hutan (Pratiwi dan Safe'i, 2018). Kesehatan hutan adalah suatu kondisi hutan yang dapat dikatakan baik sehingga mampu menjalankan fungsi hutan dengan baik sesuai dengan fungsi hutan yang telah ditentukan dan dapat menjamin keamanan investasi dan produksi, dengan tetap menjaga kerusakan atau gangguan di bawahnya dapat diterima (Safe'i et al. 2021). Berdasarkan fungsi hutan yang ada meliputi, hutan

Kerusakan pohon bisa terjadi oleh faktor biotik dan abiotik yang muncul akibat adanya dampak antara individu tanaman dengan lingkungannya (Safe'i et al. 2021). Kerusakan faktor biotik dan abiotik dari tanaman bisa terlihat dari ketidaknormalan secara langsung dilihat dari penampakan tanaman itu sendiri maupun adanya organisme pengganggu (Abimanyu et al. 2019). Noviady dan Rivai (2015) menyatakan adanya kerusakan pohon biasanya terjadi akibat serangan

Teknik Monitoring Kesehatan Hutan atau Forest Health Monitoring (FHM) merupakan teknik untuk menilai kerusakan pohon. Teknik ini berfungsi mengetahui kondisi kerusakan pohon yang terjadi pada pohon di beberapa fungsi hutan. Penggunaan Geographic Information System (GIS) produksi (didalamnya termasuk hutan rakyat), hutan konservasi dan hutan lindung (hutan kemasyarakatan/HKm) (Safe'i et al. 2019). Kurangnya kesadaran pengelola akan pentingnya kesehatan hutan dalam mencapai pengelolaan hutan lestari, padahal dengan adanya kesehatan hutan dapat mengontrol kerusakan pohon yang berada di bawah nilai ambang ekonomi yang masih bisa diterima (Safe'i et al. 2020). Intensitas pengendalian diperlukan apabila kerusakan yang terjadi sudah di atas ambang ekonomi dan jumlah biaya yang dikeluarkan tergantung dari tujuan pengelolaan dan besarnya kerugian yang terjadi (Irwanto, 2006).

hama, penyakit, gulma, satwa, api, cuaca, ataupun akibat aktivitas manusia. Menurut Safe'i et al. (2021), kerusakan pohon dapat menyebabkan terjadinya penurunan fungsi hutan. Kerusakan pohon pada waktu tertentu perlahan akan mempengaruhi laju pertumbuhan dan perkembangan pohon pada ekosistem hutan sehingga mempengaruhi dari kesehatan hutan (Rocmah et al. 2021).

menjadi vital, dimana sebaran kondisi kerusakan pohon dapat diketahui secara spasial, sehingga dapat dideskripsikan dengan baik. Penilaian kerusakan pohon dimaksud untuk menilai kategori kesehatan hutan pada berbagai fungsi hutan, sehingga keputusan apa yang bisa dilakukan oleh 
pengelola bisa akurat terkait kondisi yang sudah didapat. Oleh karena itu penelitian ini bertujuan

\section{METODE PENELITIAN}

Penelitian ini merupakan analisis dari penelitian yang sudah ada, analisis dilakukan selama 4 bulan dari bulan Januari sampai April 2020 di Hutan Konservasi (Kelompok Sistem Hutan Kerakyatan (SHK) Lestari pada Tahura Wan Abdul Rachman) terletak di koordinat $05^{\circ}$ 31' 37.98" S dan $105^{\circ} 13^{\prime}$ 14.72" E. Hutan Produksi berada di Kecamatan Batang Hari Lampung Timur yang terletak di koordinat $05^{\circ} 11$ ' $25.26^{\prime \prime} \mathrm{S}$ dan untuk menilai kerusakan pohon di beberapa fungsi hutan

$105^{\circ} 22^{\prime}$ 48.53”. Hutan Produksi tersebut merupakan Hutan Rakyat yang dikelola langsung oleh masyarakat petani sekitar. Sementara itu, Hutan Lindung pada pengelolaan Hutan Kemasyarakatan $(\mathrm{HKm})$ Beringin Jaya Kelompok Tani Lestari Jaya 8 yang terletak di koordinat $05^{\circ}$ 24'33.44" S dan $104^{\circ} 40^{\prime}$ 07.64" E dengan luas 111 ha. Lokasi penelitian dapat dilihat pada Gambar.1.

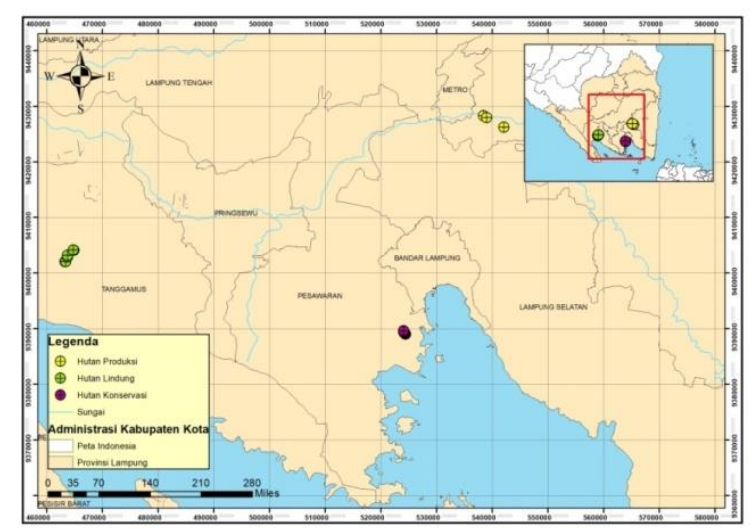

Gambar 1. Peta Lokasi Penelitian.

Alat yang digunakan pada penelitian ini adalah GNSS genggam (Global Navigation Satellite System) untuk mengambil koordinat titik klaster plot dan menentukan arah mata angin, serta laptop yang dilengkapi software ArcGIS 10.6.1 untuk memetakan kerusakan pohon pada masing-masing

Tahap pengumpulan data spasial digunakan sebagai masukan atau input data terdiri atas data lapangan, meliputi data titik-titik koordinat klaster plot pada masing-masing fungsi hutan. Peta fungsi hutan. Bahan meliputi kondisi langsung pada lokasi pengamatan di hutan kemasyarakatan (HKm) Beringin Jaya Kelompok Tani Lestari Jaya 8, hutan konservasi (Tahura Wan Abdul Rachman) dan hutan produksi yang berada di Kecamatan Batang Hari Lampung Timur.

administrasi Provinsi (sumber BKPH Provinsi Lampung), peta administrasi HKm Beringin Jaya (sumber KPH Kota Agung Utara), dan peta Tahura Wan Abdul Rachman (sumber UPT Tahura Wan 
Abdul Rachman). Setelah didapatkan data proses selanjutnya melakukan pemetaan sebaran kerusakan pohon pada software ArcGIS 10.6.1 dan

Perhitungan Indek kerusakan (IK) nantinya digunakan dalam menghitung Tree Damage Level Index (TLI) yang sudah dilakukan pada penelitian sebelumnya pada hutan lindung (Haikal et al. 2020), hutan konservasi (Indriani et al. 2020), dan

Nilai 0 akan diberikan pada kerusakan yang tidak mempunyai nilai pada tingkat keparahannya. Kerusakan yang paling parah akan dicatat pada kasus kerusakan berganda yang terjadi pada lokasi yang sama (Safe'i et al 2015). Setelah nilai TLI

dimana:

NT = nilai tertinggi dari kesehatan pohon pada individu pohon,

$\mathrm{NR}=$ nilai terendah dari kesehatan pohon pada individu pohon,

\section{HASIL DAN PEMBAHASAN}

\section{Kesehatan Pohon}

Pemetaan kerusakan pohon
mengkombinasikan antara titik sebaran pohon
dengan analisis kesehatan pohon sehingga di dapat
peta sebaran kesehatan pohon yang sudah dibedakan
tiap warnanya, untuk kondisi pohon sehat di tandai
dengan warna hijau, pohon sedang dengan warna
kuning dan kondisi pohon rusak dengan warna
merah. Jumlah pohon yang ada dibeberapa fungsi
hutan pada pengamatan berjumlah 571 pohon.

dilakukan deskripsi tentang kerusakan pohon yang didapat.

hutan produksi (Ansori et al. 2020) dengan menggunakan rumus persamaan berikut (Mangold 1997):

$$
\boldsymbol{T L I}=I K 1+I K 2+I K 3
$$

diketahui maka dilakukan Kategori Nilai Kesehatan Pohon (KNKP) dengan persamaan sebagai berikut (Safe'i et al. 2015):

$$
\boldsymbol{K N K \boldsymbol { P }}=\frac{N T-N R}{J K}
$$

JK = jumlah kategori yang sudah ditetapkan (sehat, sedang dan rusak).

Berdasarkan hasil analisis penelitian, Hutan Produksi memiliki jumlah pohon sehat relatif lebih banyak dengan jumlah 51 pohon sekaligus untuk pohon rusak terbanyak dengan jumlah 128 pohon. Kondisi pohon pada beberapa fungsi hutan disajikan pada Gambar 2. Setiap fungsi hutan memiliki jumlah pohon kesehatan pohon yang berbeda. Kondisi hutan yang memiliki jumlah pohon sehat yang banyak belum tentu memiliki persentase kesehatan pohon yang paling besar. 


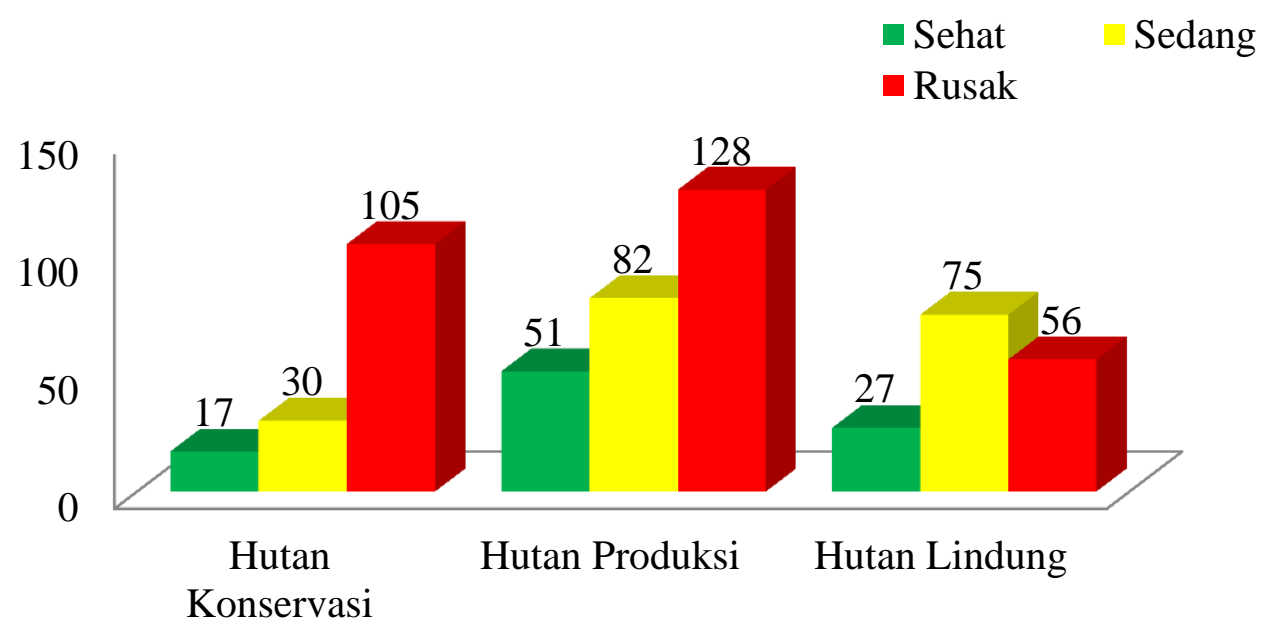

Gambar 2. Kondisi Pohon pada Beberapa Fungsi Hutan.

\section{Hutan Konservasi}

Berdasarkan pemetaan partisipatif Tahun 2010 luasan $829 \mathrm{Ha}$ adalah wilayah kelola dari Kelompok Sistem Hutan Kerakyatan (SHK) Lestari, terletak pada kawasan Taman hutan Raya Wan Abdul Rahman. Menurut Dinas Kehutanan Propinsi Lampung (2009) Pengelolaan Tahura WAR membagi kawasan Tahura WAR menjadi beberapa blok pengelolaan, yaitu blok perlindungan, blok koleksi, blok pemanfaatan, dan blok lainnya (penelitian, pendidikan, dan social forestry). Penelitian (Handoko dan Darmawan,

Jenis pohon yang ditemui berjumlah 20 jenis pada hutan konservasi meliputi Jengkol (Achidendron pauciflorum), Durian (Durio zibethinus), Petai (Parkia speciosa), Sengon Buto (Enterolobium cylocarpum), Melinjo (Gnetum gnemon), Kemiri (Aleurites moluccanus), Rambutan (Naphelium lappaceum), Waru (Hibiscus tiliaceus), Alpukat (Persea americana), Karet (Hevea

konservasi ini menunjukkan kriteria yang rendah. Komunitas dengan keanekaragaman tinggi akan lebih mantap terhadap gangguan
2015) menyatakan bahwa blok pada Tahura WAR sudah mengalami degadrasi. Lahan pada pengelolaan hanya bisa dilewati oleh sepeda motor dikarenakan jalan yang masih tanah sehingga lebar jalan tidak lebih dari 2 meter. Ketinggian pada Tahura WAR memiliki rentan 250-300 mdpl, tingkat kemiringan pada hutan ini berkisar $5-40^{\circ}$ wilayah kelola SHK Lestari merupakan memiliki suhu yang rata-rata $20-29^{\circ} \mathrm{C}$ dan beriklim tropis basah dengan curah hujan antara 2500-3000 $\mathrm{mm} / \mathrm{tahun}$.

brasiliensis), Bayur (Pterospermum javanicum), Dadap (Erythrina variegate), Johar (Cassia siamea), Salam (Syzygium polyanthum), Cengkeh (Syzygium aromaticum), Randu (Durio zibethinus), Nangka (Artocarpus heterophyllus), Saga (Adenanthera pavonina), Beringin (Ficus benjamina) dan Mangga (Mangifera indica). Hasil keanekaragaman pohon pada hutan

lingkungan/iklim (Wahyudi et al. 2014). Pohon Durian merupakan pohon yang paling banyak berada pada hutan ini. Pohon durian merupakan 
jenis pohon MPTS yang memiliki nilai ekonomi serta dapat dijadikan sebagai tanaman pelindung (Awang et al. 2016).

Kerusakan pohon pada hutan konservasi memiliki kerusakan yang tinggi hal ini didapat dari analisis penelitian dimana pohon rusak dominan pada klaster plot sampel. Sebaran kerusakan pohon pada klaster plot dapat dilihat pada Gambar 3.

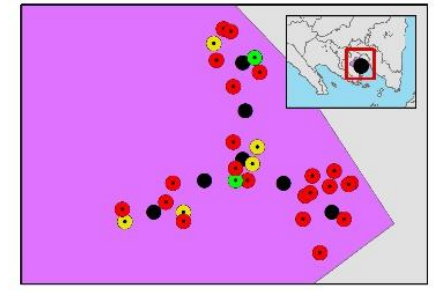

Cluster Plot 1

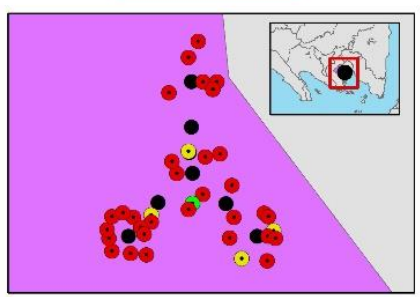

Cluster Plot 4

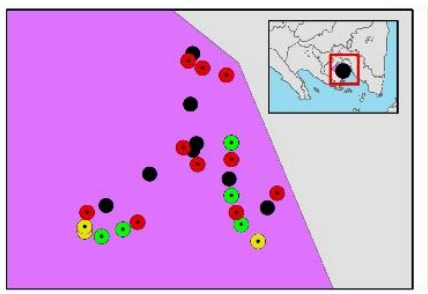

Cluster Plot 2

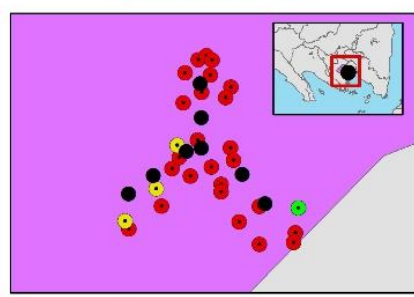

Cluster Plot 5

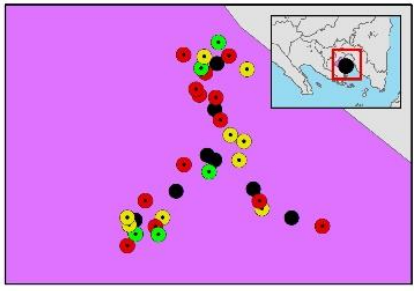

Cluster Plot 3

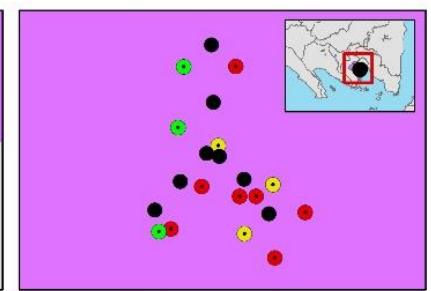

Cluster Plot 6

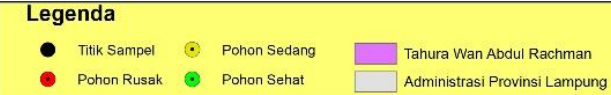

Gambar 3. Sebaran Kerusakan Pohon pada Hutan Konservasi.

Kondisi kerusakan pohon rusak tinggi yang didapat dari analisis didominasi pada klaster plot 4 dan 5. Kerusakan berupa daun yang rusak (berlubang dan berubah warna), diikuti oleh cabang patah/mati serta luka terbuka menjadi yang paling banyak ditemui (Indriani et al. 2020). Kerusakan tersebut menunjukkan bahwa kerusakan yang terjadi pada kasus hutan konservasi tidak hanya dari faktor biotik (manusia, binatang atau organisme

Kerusakan berupa daun, pucuk atau tunas yang rusak diakibatkan adanya hama yang memakan daun-daun tersebut. Kondisi kerusakan pada pohon yang terjadi dapat berpengaruh terhadap pertumbuhan dan ekosistem (Abimanyu et al. lain) melainkan faktor abiotik (topografi, cahaya matahari) juga (Safe'i et al. 2020). Kerusakan pohon sebaiknya dideteksi sedini mungkin sehingga memungkinkan untuk tindakan perawatan pohon yang tidak sehat dan dapat meminimalisir kerusakan pohon (Safe'i et al. 2018). Deteksi dapat menghindari kecelakaan disebabkan oleh pohon tumbang (Rahmawaty et al. 2018).

2019), seperti hilangnya pucuk dan daun yang rusak karena hama merupakan tipe kerusakan pada pohon yang dapat menghambat terjadinya proses fotosintesis. Pohon dengan kondisi kerusakan cabang patah/mati mengakibatkan pertumbuhan 
yang menurun, kehilangan biomassa, sampai menyebabkan kematian, serta berpengaruh langsung terhadap kesehatan hutan (Nuhamara dan Kasno, 2001). Kerusakan selanjutnya terjadi seperti hilangnya pucuk dominan/mati dengan

\section{Hutan Produksi}

Hutan Produksi pada pengamatan merupakan hutan rakyat yang ada di Kecamatan Batang Hari Lampung Timur. Hutan rakyat merupakan hutan yang dikelola oleh petani atau penggarap secara langsung, mlilik perorangan/sendiri yang menerapkan prinsip hutan yang lestari, terdiri dari satu jenis atau bahkan berbagai jenis pepohonan (Lembaga Penelitian Institut Pertanian Bogor, 1990).

Jenis pohon berjumlah 19 jenis yang ditemui pada fungsi hutan ini meliputi: Mangium (Acacia mangium), Kluek (Pangium edule), Jati (Tectona grandis), Karet (Hevea braziliensis), Nangka (Artocarpus heterophyllus), Sengon (Paraserienthes falcataria), Randu (Ceiba pentandra), Jabon (Neolamarckia cadamba), Petai Cina (Leucaena leucocephala), Medang (Phoebe

Hutan Produksi memiliki pohon sehat lebih sedikit dibandingkan pohon rusak seluruh pohon yang ada. Hal ini menunjukkan bahwa di hutan produksi ini pada keadaan rusak (Gambar 4). Kerusakan pohon akan berpengaruhi pada produktivitas pohon jika kerusakan pohon tinggi sehingga mengakibatkan produksi maupun, produktivitas lahan hutan sedikit (Ansori et al.

Kerusakan yang dominan pada Hutan Produksi terjadi pada kerusakan pada cabang pohon, sejalan dengan penelitian Tsani dan Safe'i ditemukannya pohon yang tajuknya hilang sebagaian karena mati pucuk. Mati pucuk dapat disebabkan oleh penyakit, hama dan kekeringan (Safe'i et al. 2019).

hunanensis), Akasia (Acacia auriculiformis), Sengon (Albizia chinensis), Pulai (Alstonia scholaris), Wareng (Gmelina arborea), Jengkol (Archidendron pauciflorum), Waru (Hibiscus tiliaceus), Bayur (Pterospermum javanicum), Dadap (Erythrina variegata), Johar (Senna siamea) dan Petai (Parkia speciosa). Pohon pada hutan ini didominasi oleh mangium yang berada pada klaster plot 1 dan 2. Hal ini dikarenakan hutan rakyat tersebut menggunakan pola tanam monokultur yang dimaksudkan pola tanam dengan penanaman yang sejenis sehingga memiliki keanekaragaman rendah. Keanekaragaman yang rendah dalam suatu ekosistem secara fisik terkendali dan mendapat aktivitas budidaya (Wahyudi et al. 2014).

2020). Pengelolaan hutan rakyat hal yang paling diutamakan yaitu produktivitas oleh karena itu indikator produktivitas sangat penting. Apalagi pada pola tanam agroforestri yang merupakan salah satu ekosistem hutan produksi yang berfungsi untuk menjamin produksi kayu (Safe'i et al. 2015; Safe'i et al. 2019).

(2017) menyatakan bahwa kerusakan cabang terjadi karena adanya serangan hama, gulma maupun akibat kegiatan manusia. Kerusakan lainnya yaitu 
kerusakan pada luka terbuka yang mempengaruhi keberlangsungan hidup dan menyebabkan kematian pada pohon. Adanya aktivitas manusia menyebabkan terjadinya luka terbuka berupa pengelupasan kulit batang pohon (Sitinjak et al. 2016). Kerusakan cabang patah atau mati juga disebabkan terganggunya proses fotosintesis pada pohon yang akan menimbulkan proses transfer unsur hara menuju kedaun menjadi terhambat (Safe'i et al. 2018;Safe'i et al. 2019). Pemangkasan cabang menjadi salah satu cara penanggulangan kerusakan ini, sehingga cabang tidak akan patah dengan sendirinya dan akan mengurangi kerusakan pohon yang terjadi (Safe'i et al. 2020).

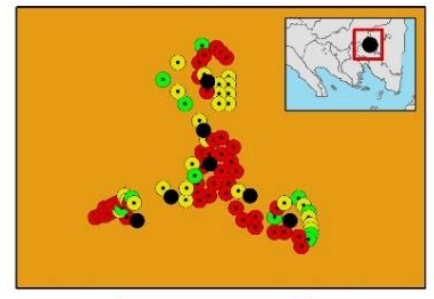

Cluster Plot 1

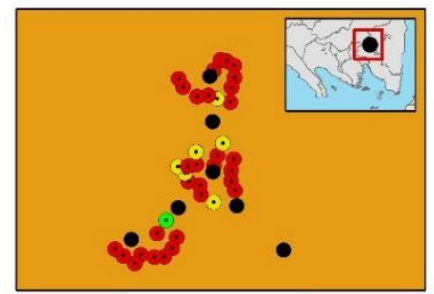

Cluster Plot 4

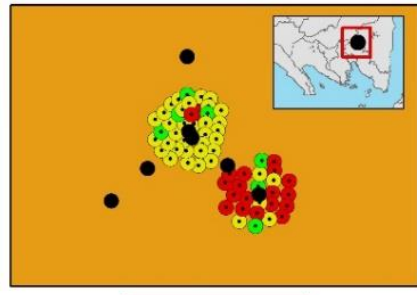

Cluster Plot 2

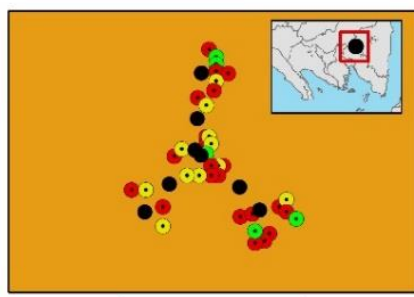

Cluster Plot 5

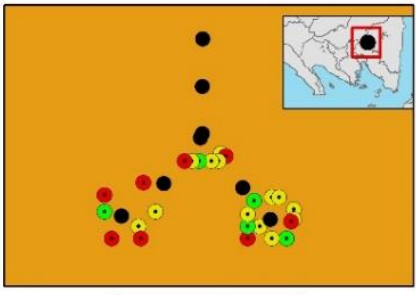

Cluster Plot 3

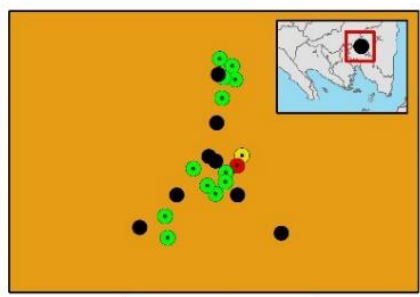

Cluster Plot 6

\section{Hutan Lindung}

Gambar 4. Sebaran Kerusakan Pohon pada Hutan Produksi.

Hutan Lindung pada pengelolaan Hutan Kemasyarakatan (HKm) Beringin Jaya Kelompok Tani Lestari Jaya 8 merupakan bagian dari Kesatuan Pengelolaan Hutan Lindung (KPHL) Model Kota Agung Utara (Unit X) terletak di Kabupaten Tanggamus Provinsi Lampung. Penerapan skema HKm pada lahan hutan lindung harus sesuai dengan peraturan, Penanaman dengan pola tanam agroforestry harus dengan ketentuan tanaman tajuk tinggi harus lebih mendominasi agar fungsi utama hutan lindung tetap terjaga (Septiawan et al. 2017).
Data keadaan lahan kritis menunjukkan bahwa sebagian besar lahan di dalam kawasan KPH Kota Agung Utara berupa lahan sangat kritis, kritis dan potensial kritis (Suratman, 2014). Lahan hutan lindung tersebut mimiliki tingkat kelerengan yang curam sehingga banyak petani menanam tanaman sayuran misalnya buncis, kol, kacang panjang, cabe, bawang, kentang, dan tomat. Aktivitas petani banyak ditemui pada ketinggian 250 mdpl sampai batas kawasan hutan dengan batas hutan alam di atasnya sampai pada ketinggian $1.000 \mathrm{mdpl}$ atau lebih. 
Jenis pohon pada hutan lindung berjumlah 34 jenis meliputi Jambon (Neolamarckia cadamba), Waru Gunung (Hibiscus similis), Kayu Pasang (Quercus sundaica), Sintuk (Cinnamomum malabatrum), Cengkeh (Syzygium aromaticum), Jeruk Hitam (Citrus macroptera), Medang (Schima wallichii), Walik Angin (Mallotus paniculatus), Kayu Amplas (Ficus ampelas), Cempaka Telur (Magnolia liliifera), Cempaka Kuning (Magnolia champaca), Tutup Putih (Mallotus paniculatus), Meniran (Phyllanthus urinaria), Cempaka (Magnolia champaca), Kelengkeng Hutan (Dimocarpus longan), Meranti Merah (Shorea macrophylla), Flamboyan (Delonix Regia), Merbau

Hutan Lindung secara umum dalam kondisi sedang. Hal ini karena jumlah pohon berstatus sedang tinggi dari total pohon yang ada, sedangkan status sehat yang ditemukan tidak banyak (Gambar 5). Hal ini disebabkan masyarakat pemegang
(Intsia bijuga), Kayu Air-air (Jackia ornate), Rimau (Toona sureni), Petai (Parkia speciosa), Mahoni (Swietenia macrophylla), Bayur (Pterospermum celebicum), Waru (Hibiscus tiliaceus), Sengon (Albizia chinensis), Petai Cina (Leucaena leucocephala), Jengkol (Archidendron pauciflorum), Randu (Ceiba pentandra), Mindi (Melia azedarach), Sono Keling (Dalbergia latifolia), Nangka (Artocarpus heterophyllus), Alpukat (Persea Americana), Melinjo (Gnetum gnemon) dan Mangga (Mangifera indica).

IUPHKm menanam tanaman pertanian sebagai sumber penghasilan utama, sehingga kondisi hutan lindung yang sebelumnya banyak ditemui pepohonan dirubah menjadi lahan pertanian.
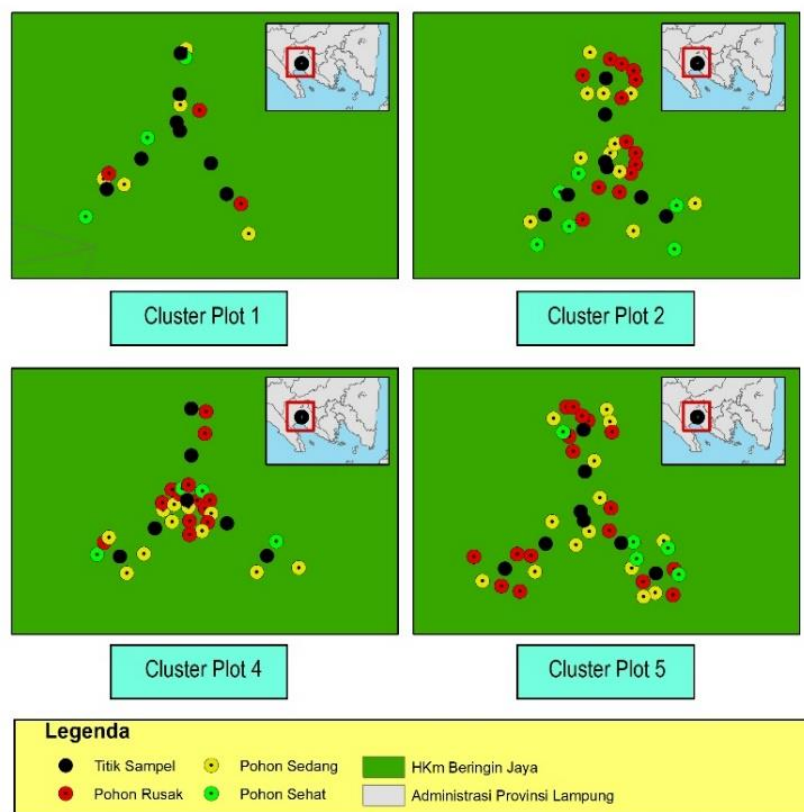

Cluster Plot 5
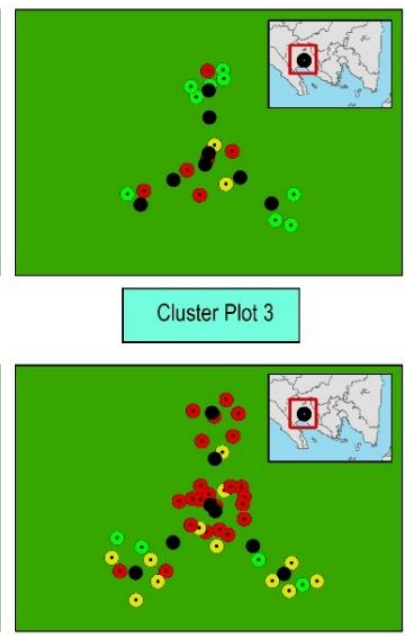

Cluster Plot 6

Gambar 5. Sebaran Kerusakan Pohon pada Hutan Lindung. parah pada pohon yang dilakukan pengamatan. 
Kerusakan terbesar yang didapat pada klaster 6 terjadi karena kondisi pohon yang sudah tua. Kondisi pohon yang tua akan menyebabkan batang/cabang patah atau mati dikarnakan terjadinya pelapukan yang disebabkan oleh jamur (Pertiwi et al. 2019). Kerusakan pada pohon Jambon (Neolamarckia cadamba) mendapat hasil kerusakan terbanyak, kerusakan banyak terjadi

Kerusakan daun pucuk/tunas rusak, matinya bagian pucuk yang kemudian meluas kebagian yang lebih tua serta perubahan warna pada daun merupakan tada/ gejala dari kerusakan daun pucuk (Rezinda et al. 2021). Lebih lagi (Safe'i et al. 2019) menjelaskan bahwa kerusakan bagian pucuk tanaman juga disebabkan oleh

\section{KESIMPULAN}

Pemetaan kerusakan pohon dibedakan tiap warnanya, untuk kondisi pohon sehat di tandai dengan warna hijau, pohon sedang dengan warna kuning dan kondisi pohon rusak dengan warna merah. Kondisi kesehatan pohon pada hutan konservasi untuk pohon sehat sebanyak 17, pohon sedang sebanyak 30 dan pohon rusak sebanyak 105. Hutan produksi kondisi kesehatan pohon yang didapat yaitu untuk pohon sehat sebanyak 51, pohon sedang sebanyak 82 dan pohon rusak

\section{DAFTAR PUSTAKA}

Abimayu B., Safe'i R. dan Hidayat W. 2019. Aplikasi Metode Forest Health Monitoring dalam Penilaian Kerusakan Pohon di Hutan Kota Metro. Jurnal Sylva Lestari. 7 (3): 289298.

Ansori, D.P., Safe'i, R. dan Kaskoyo, H. 2020. Penilaian Indikator Kesehatan Hutan Rakyat pada Beberapa Pola Tanam (Studi kasus di Desa Buana Sakti, Kecamatan Batang Hari, Kabupaten Lampung Timur). Jurnal Perennial. 16 (1): 1-6.

Ardiansyah, F. dan Safe'i, F. 2021. Analysis of pada cabang patah atau mati gejala dan tipe kerusakan berupa hilangnya daun, ranting dan dengan diikuti pelapukan cabang yang mati (Haikal et al. 2020). Hal ini sesuai pernyataan Utami dan Ismanto (2015) bahwa keadaan pohon yang terserang hama dan penyakit biasanya pohon yang sudah berumur tua, yang berkurangnya metabolisme tubuh pohon.

serangan hama penggerek, bakteri, musim kemarau, serta drainase dan aerasi rendah. Rikto (2010) mengatakan bahwa kondisi pertumbuhan tanaman lambat dan rentan akan gangguan penyakit atau hama dipengaruhi oleh kondisi lingkungan dan tempat tumbuh tanaman yang kurang mendukung.

sebanyak 128. Sedangkan untuk hutan lindung kondisi pohon sehat sebanyak 27, pohon sedang sebnyak 75 dan pohon rusak sebanyak 56. Kondisi kesehatan pohon pada beberapa fungsi hutan dalam kondisi rusak dan perlu perhatian dari pengelola hutan. Perlu adanya tindakan oleh pengelola berupa pemeliharaan seperti pendangiran, pemupukan, pemangkasan, serta tindakan pemanenan dengan pemilihan waktu yang tepat.

Changes in Health of Coastal Mangrove Forest on the East Coast of Lampung. IOP Conf. Series: Earth and Environmental Science 755. 012028.

Awang, A., S. Sadono, R., Purwanto, H. R. dan Sanudin. 2016. Perkembangan Hutan Kemasyarakatan di Provinsi Lampung (Progress of Community Forest in Lampung Province. Jurnal Manusia dan Lingkungan. 23(2): 276-283.

Dinas Kehutanan Provinsi Lampung. 2009. Buku Informasi Tahura. Bandar Lampung. 38 p.

Haikal, F. F., Safe'i, R., Kaskoyo, H. dan 
Darmawan, A. 2020. Pentingnya Pemantauan Kesehatan Hutan dalam Pengelolaan Hutan Kemasyarakatan (Studi Kasus HKm Beringin Jaya yang di Kelola oleh KTH Lestari Jaya 8). Jurnal Hutan dan Pulau-pulau Kecil.4(1): 3147.

Handoko. dan Darmawan, A. 2015. Perubahan Tutupan Hutan di Taman Hutan Raya Wan Abdul Rachman (Tahura WAR). Jurnal Sylva Lestari. 3(2): 43-52.

Indriani, Y., Safe'i, R., Kaskoyo, H. dan Darmawan, A. 2020. Vitalitas Sebagai Salah Satu Indikator Kesehatan Hutan Konservasi. Jurnal Perennial. 16(2): 40-46.

Irwanto. 2006. Penilian kesehatan hutan tegakan jati (Tectona grandis) dan eucalyptus (Eucalyptus pellita) pada Kawasan Hutan Wanagama I. Pascasarjana. Buku. Universitas Gajah Mada. Yogyakarta. $66 \mathrm{hlm}$.

Lembaga Penelitian Institut Pertanian Bogor. 1990. Sistem Pengelolaan Hutan Rakyat. Lembaga Penelitian Institut Pertanian Bogor. Bogor.

Mangold R. 1997. Forest Health Monitoring: Field Methods Guide. USDA Forest Service, USA. 197p.

Noviady, I. dan Rivai, R. R. 2015. Identifikasi Kondisi Kesehatan Pohon Peneduh di Kawasan Ecopark, Cibinong Science CenterBotanic Gardens. in: Prosiding Seminar Nasional Masyarakat Biodiversitas Indonesia ITB Bandung. 1385-1391.

Nuhamara, S. T. dan Kasno. 2001. Present Status of Crown Indicators. Di dalam: Forest Health Monitoring to Monitor The Sustainability of Indonesian Tropical Rain Forest. Volume I. Japan: ITTO dan Bogor: SEAMEOBIOTROP. 124p.

Pertiwi, D., Safe'I, R., Kaskoyo, H. dan Indriyanto. 2019. Identifikasi Kondisi Kerusakan Pohon Menggunakan Metode Forest Health Monitoring Di Tahura WAR Provinsi Lampung. Jurnal Perennial. 15(1): 1-7.

Pratiwi S.L. dan Safe'i, R. 2018. Penilaian vitalitas pohon jati dengan forest health monitoring di KPH Balapulang. Jurnal Ecogreen. 4(1): 915.

Rahmawaty., Sembiring, I. E. P., Batubara, R. dan Patana, P. 2018. Mapping of Tree Damage
Classification in The Western Part of Medan City Green Belts Using Geographic Information System. IOP Conf. Series: Earth and Environmental Science. 275:1-8.

Rezinda, C.F.G., Safe'i, R., dan Kaskoyo, H. 2021. Status dan Perubahan Indikator Vitalitas Hutan Konservasi Taman Hutan Raya Wan Abdul Rachman. Jurnal Perennial. 17(1): 1218.

Rikto. 2010. Tipe Kerusakan Pohon Hutan Kota (Studi Kasus: Hutan Kota Bentuk Jalur Hijau, Kota Bogor-Jawa Barat). Institut Pertanian Bogor.

Rocmah, S.F., Safe'i, R., Bintoro, A., Kaskoyo, H. dan Rahmat, A. 2021. The effect of forest health on social conditions of the community. IOP Conf. Series: Earth and Environmental Science. 739. 012016.

Safe'i, R., Christine, W. dan Hari, K. 2019. Penilaian kesehatan hutan pada berbagai tipe hutan di Provinsi Lampung. Jurnal Sylva Lestari. 7 (1): 95-109.

Safe'i, R., Darmawan, A., Kaskoyo, H. dan Rezinda, C.F.G. 2021. Analysis of Changes in Forest Health Status Values in Conservation Forest (Case Study: Plant and Animal Collection Blocks in Wan Abdul Rachman Forest Park (Tahura WAR)). Journal of Physics: Conference Series. 1842. 012049 .

Safe'i, R., Erly, H. Christine, W. dan Hari, K. 2018. Analisis Keanekaragaman Jenis Pohon Sebagai Salah Satu Indikator Kesehatan Hutan Konservasi. Jurnal Perennial. 14(2): 32-36.

Safe'i, R., Hardjanto, Supriyanto. dan Sundawati, L. 2015. Pengembangan Metode Penilaian Kesehatan Hutan Rakyat Sengon (Falcataria Moluccana (Miq.) Barneby \&amp; J.W. Grimes). Jurnal Penelitian Hutan Tanaman. 12(3): 175-187.

Safe'i, R., Indriani, Y., Darmawan, A. dan Kaskoyo, H. 2019. Status Pemantauan Kesehatan Hutan yang Dikelola Oleh Kelompok Tani Hutan SHK Lestari: Studi Kasus Kelompok Tani Hutan Karya Makmur I Desa Cilimus, Kecamatan Teluk Pandan, Kabupaten Pesawaran, Provinsi Lampung. Jurnal Silva Tropika. 3 (2): 185-198. 
Safe'i, R., Kaskoyo, H., Darmawan, A. 2020. Analisis Kesehatan Pohon Dengan Menggunakan Metode Forest Health Monitoring (Studi Kasus pada Tiga Fungsi Hutan di Provinsi Lampung). Prosiding Seminar Nasional Konservasi 2020. 243-249.

Safe'i, R., Kaskoyo, H., Darmawan, A. dan Indriani, Y. 2020. Kajian Kesehatan Hutan Dalam Pengelolaan Hutan Konservasi. Ulin - Jurnal Hutan Tropis. 4(2): 70-76.

Safe'i, R., Latumahina, F.S., Dewi, B.S. dan Ardiansyah, F. 2021. Short Communication: Assessing the state and change of forest health of the proposed arboretum in Wan Abdul Rachman Grand Forest Park, Lampung, Indonesia. Biodiversitas. 22(4): 2072-2077.

Safe'i, R., Latumahina, F.S., Suroso, E. dan Warsono. 2020. Identification of durian tree health (Durio Zibethinus) in the Prospective Nusantara Garden Wan Abdul Rachman Lampung Indonesia. Jurnal Plant Cell Biotechnology and Molecular Biology 21, 41(42). 103-110.

Safe'i, R., Sari, R.N., Iswandaru, D., Latumahina, F.S., Taskirawati, I. dan Kaskoyo, H. 2021. Biodiversity and Site Quality as Indicators of Mangrove Forest Health Pasir Sakti, Indonesia. 25(2): 4400- 4410.

Septiawan, W., Indriyanto. dan Duryat. 2017. Jenis Tanaman, Kerapatan, dan Stratifikasi Tajuk pada Hutan Kemasyarakatan Kelompok Tani Rukun Makmur 1 Di Register 30 Gunung Tanggamus, Lampung. Jurnal Sylva Lestari. 5(2): 88-101.

Sitinjak, E.V., Duryat. dan Santoso, T. 2016. Status kesehatan pohon pada jalur hijau dan halaman parkir Universitas Lampung. Jurnal Sylva Lestari. 4(2). 101-108.

Suratman. 2014. Rencana Pengelolaan Hutan Jangka Panjang Kesatuan Pengelolaan Hutan Lindung Kota Agung Utara 2014-2023. KPHL Kota Agung Utara. Kota Agung Utara.

Tsani MK. dan Safe'i R. 2017. Identifikasi tingkat kerusakan tegakan pada kawasan pusat pelatihan gajah Taman Nasional Way Kambas. Jurnal Hutan Tropis. 5(3): 215-221.

Utami, S. dan Ismanto, A. 2015. Serangan Hama
Defoliator Pada Pola Tanam Monokultur dan Agroforestri Jabon. Jurnal Sains Natural Universitas Nusa Bangsa. 5 (1) : 42-48.

Wahyudi, A., Harianto, S.P. dan Darmawan, A. 2014. Keanekaragaman Jenis Pohon di Hutan Pendidikan Konservasi Terpadu Tahura Wan Abdul Rachman. Jurnal Sylva Lestari. 2(3): 1-10. 